\title{
Development of a Rapidly Deployed Department of Energy Emergency Response Element
}

R.J. Tighe*, C.A. Riland*, and R.C. Hopkins*

Abstract: The Federal Radiological Emergency Response Plan (FRERP) directs the Department of Energy (DOE) to maintain a viable, timely, and fully documented response option capable of supporting the responsible Lead Federal Agency in the event of a radiological emergency impacting any state or United States territory (e.g., CONUS). In addition, the DOE maintains a response option to support radiological emergencies outside the continental United States (OCONUS). While the OCONUS mission is not governed by the FRERP, this response is operationally similar to that assigned to the DOE by the FRERP. The DOE is prepared to alert, activate, and deploy radiological response teams to augment the Radiological Assistance Program and/or local responders. The Radiological Monitoring and Assessment Center (RMAC) is a phased response that integrates with the Federal Radiological Monitoring and Assessment Center (FRMAC) in CONUS environments and represents a stand-alone DOE response for OCONUS environments. The FRMAC/RMAC Phase I was formally "stood up" as an operational element in April 1999. The FRMAC/RMAC Phase II proposed "stand-up" date is midyear 2000.

\footnotetext{
*Bechtel Nevada

Remote Sensing Laboratory

P.O. Box 98521, M/S RSL-24

Las Vegas, NV 89193-8521
} 


\section{Introduction}

A Federal Radiological Monitoring and Assessment Center (FRMAC) is established in response to the Lead Federal Agency (LFA) or state request when a major radiological emergency is anticipated or has occurred. The FRMAC becomes a coalition of federal off-site monitoring and assessment activities to assist the LFA, state(s), local, and tribal authorities. State, local, and tribal authorities are invited to co-locate and prioritize monitoring and assessment efforts in the FRMAC. The Department of Energy (DOE) is tasked by the Federal Radiological Emergency Response Plan (FRERP) [FR 1996] to coordinate the FRMAC.

A FRMAC provides an operational framework for coordinating and managing off-site radiological monitoring and assessment activities during a radiological emergency to support the LFA and state(s) in a timely manner [DOE 1992a, DOE/NV 1998, DOE/NV 1997]. A FRMAC is tasked to accomplish the following:

- Provide, in cooperation with other federal components, the personnel and equipment to coordinate and perform environmental monitoring and assessment activities.

- Request supplemental assistance and technical support from other federal agencies when needed and when considered necessary to maintain the credibility of the off-site assessment.

- Manage the responding FRMAC resources in the most time-effective and efficient manner possible to support the needs of the LFA and state(s).

- Manage and direct the federal, off-site, environmental, radiological monitoring, assessment, and evaluation activities. Maintain a FRMAC liaison with state, local, and tribal authorities with similar responsibilities.

- Maintain a common set of off-site, environmental, radiological monitoring data in an accountable and retrievable form and ensure the technical integrity of the data.

- Provide data and interpretations as well as exposure-rate contours, dose projections (including future radiation levels and potential dose commitments), and other requested radiological assessments to the LFA, state(s), or other designated agencies or jurisdictions as quickly as possible.

- Support the LFA in providing off-site monitoring, analysis, and assessment to meet the LFA requirements. Provide data to the LFA for developing the Protective Action Recommendations and promote the involvement of other federal agencies in this process.

- Provide technical and medical advice for handling radiological contamination.

- Assist in planning the recovery of the off-site area and promote the involvement of agencies having radiological expertise in participating with the federal, state, and local agencies. This recovery may involve planning for decontamination, reentry, relocation, and return.

- Transition responsibility to the Environmental Protection Agency in the post-emergency phase.

The DOE has extended its response mission beyond the FRERP requirements to include radiological emergency situations outside the continental United States (OCONUS). As this mission does not fall under the auspices of the FRERP, the response is designated as a Radiological Monitoring and Assessment Center (RMAC). The composition of the DOE components of the FRMAC and RMAC response teams, as well as their technical and operational capabilities, is nearly identical. 
The response scenarios for these teams include any and all radiological emergencies or incidents worldwide. A Phase I response is primarily designed for an initial rapid response in United States territory (CONUS). An integrated Phase I/Phase II response is designed to provide a 24-hour-aday minimum credible response for CONUS and OCONUS missions. CONUS scenarios include any DOE response more extensive than those provided by a Radiological Assistance Program (RAP) team. This may include nuclear power plant accidents, DOE site emergencies involving radioactive materials, nuclear weapons accidents, radiation transportation accidents, breached radioactive source incidents, commercial nuclear facility accidents, Weapons of Mass Destruction incidents involving nuclear materials, and other unique events (such as re-entry of satellites containing nuclear materials or Uranium Hexaflouride cylinder reprocessing).

This document defines the FRMAC/RMAC phased response, focusing primarily on Phase I and Phase II operations. A Phase III operation represents the classic "full FRMAC" response. Emphasis is placed on team makeup, technical and operational capabilities, response posture, and deployment.

The FRMAC/RMAC Phase I was formally "stood up" as an operational element in April 1999. The FRMAC/RMAC Phase II proposed "stand-up" date is midyear 2000.

\section{Concept of Operations}

The phased FRMAC/RMAC will be implemented by Bechtel Nevada as directed and advised by the Department of Energy - Nevada Operations Office (DOE/NV), Emergency Management Division, in support of the Department of Energy - Headquarters, Office of Emergency Response, Defense Programs 23 (DP-23). This response will be consistent with recent Presidential Decision Directives, the FRERP, and relevant existing FRMAC documentation. In addition, the phased FRMAC/RMAC will be fully integrated with the other DOE emergency response assets, including:

- Radiological Assistance Program (RAP) [DOE 1992b]

- Accident Response Group (ARG) [DOE 1991a]

- Aerial Measuring Systems (AMS) [DOE 1991b]

- Atmospheric Release Advisory Capability (ARAC) [Weinstein and Hogan 1996]

- Radiological Emergency Assistance Center/Training Site (REAC/TS) [Weinstein and Hogan 1996]

The phased response is based upon lessons learned from DOE participation in recent radiological exercises, as well as examination of real world responses. For example, the ability of the team to assist first responders into potentially contaminated areas and to train state and local responders on civilian monitoring practices was built from examination of the responses to the Oklahoma City bombing and the Goiaina, Brazil, cesium-137 accident.

The following Mission Statement guided the design and implementation of the phased FRMAC/RMAC: 
DOE/NV and Bechtel Nevada will provide a rapid, responsive radiological consequence management option for the emergency response community that is phased, flexible, integrated, and designed to utilize state of the art monitoring and assessment technologies.

To efficiently carry out this mission, all components of the phased FRMAC/RMAC program will be coordinated and planned, to include operations, training, exercises, planning, technical integration, readiness, and equipment maintenance. Capabilities will be clearly defined, proven, and numerically measured when possible. Realistic, no-notice drills will be used to evaluate, assess, and demonstrate capabilities. In addition, DOE-planned exercises will allow for external evaluation of the program. Lessons learned as a result of these exercises will be tracked and implemented as appropriate.

\subsection{Phase I}

Members of the Phase I team provide the initial interface to state, local, and/or RAP representatives. Phase I represents an immediate, minimum credible technical response with the ability to perform limited radiological monitoring and sampling, perform data assessment, provide initial characterization of the radiological situation, and prepare for the arrival of additional personnel and assets.

\subsubsection{Team Makeup}

The Phase I team consists of $15 \mathrm{DOE} / \mathrm{NV}$ and Bechtel Nevada contractor personnel:

- Director (DOE/NV)

- Operations Manager (DOE/NV)

- Assessment Supervisor

- Monitoring Supervisor

- Health and Safety Specialist

- Communications Specialist

- Logistics Specialist

- Geographic Information System (GIS) Scientist

- Database Specialist

- Monitoring Specialist [operates High Purity Germanium (HPGe) In Situ System]

- Field Monitoring Specialists (5)

Figure 1 provides the field organization for the Phase I response. The majority of the Field Monitoring Specialists are drawn from the pool of Radiation Control Technicians assigned to the Nevada Test Site. Brief position descriptions are provided below.

\section{$\underline{\text { Director }}$}

The Director sets priorities for the FRMAC. The Director is responsible for the overall execution and success of the initial emergency response. The Director also establishes and maintains communications with the LFA, state(s), and participating federal agencies while carrying out established objectives and operations. 


\section{Operations Manager}

The Operations Manager assists the Director in implementing and executing field operations and coordinating use of resources. This manager advises the Director about staff and emergency functions and monitors the implementation and status of requests and events. The Operations Manager is responsible for the management of the team, data products, and the overall safety and associated risks of specific operations before they are implemented.

\section{$\underline{\text { Assessment Supervisor }}$}

The Assessment Supervisor initially coordinates the technical deployment activities and is responsible for identifying needed equipment, personnel, and other resources. The Assessment Supervisor is generally a DOE contractor.

The Assessment Division is responsible for handling, processing, evaluating, assessing, maintaining, and reporting all radiological data gathered by the field teams. The Phase I FRMAC Assessment Supervisor evaluates initial ARAC data, performs detailed analysis of HPGe In Situ results, develops dose calculations and radiological data interpretations for advice to the LFA and/or the states, and coordinates efforts of the GIS Scientist and Database Specialist.

\section{$\underline{\text { Monitoring Supervisor }}$}

The Monitoring Supervisor evaluates the need for field information, develops plans for obtaining measurements and samples, and directs monitoring teams. The Monitoring Supervisor will accompany the FRMAC Director to the Advance Party meeting with the LFA, state, and local emergency response coordinators. The Monitoring Division provides monitoring measurements and derived analytical data of acceptable quality in a time frame that meets DOE requirements.

\section{$\underline{\text { Health and Safety Specialist }}$}

The Health and Safety Specialist is responsible for health and safety issues affecting deployed personnel. This person provides an overview to the Director about the health effects and environmental impacts of the emergency. This specialist ensures personnel radiation exposure is within the appropriate exposure standards. Other responsibilities include issuing personnel dosimetry, contamination control, and ensuring proper waste management.

\section{Communications Specialist}

The Communications Specialist provides coordination and guidance for communications services and equipment. This individual ensures that communications and frequency requirements are arranged and established during operation. 


\section{$\underline{\text { Logistics Specialist }}$}

The Logistics Specialist carries out initial logistics operations for the Phase I team. The Logistics Specialist is responsible for providing administrative, logistical, security, facilities, and mechanical systems support to deployed personnel. In addition, the Logistics Specialist prepares for the arrival of follow-on assets.

\section{$\underline{\text { GIS Scientist }}$}

The GIS Scientist is responsible for the capture, storage, retrieval, and display of radiological data. Plots are produced with contours of radiation data, dose projections, and/or federal protective action recommendations associated with spatial and geographical data such as maps and aerial photographs. GIS can also provide maps for field teams.

\section{$\underline{\text { Database Specialist }}$}

The Database Specialist prioritizes, organizes, and inputs radiological, environmental, geographic, and other pertinent information into the FRMAC database system. A variety of data reports can be generated, as needed. The database personnel are responsible for creating and maintaining the comprehensive, traceable, and quality-assured database. This individual will serve as radio control for field teams during Phase I deployment.

\section{Field Monitoring Specialists (6)}

Field Monitoring includes one HPGe In Situ Measurement Specialist. This individual makes HPGe In Situ measurements and performs standardized analysis of spectral data. Field Monitoring Specialists execute monitoring and sampling duties according to standard operating procedures. Field monitoring is conducted under the direction of the Monitoring Supervisor. Field Monitoring Specialists can accompany first responders into potentially contaminated situations during lifesaving activities. Field Monitoring Specialists can integrate with local and RAP response teams to ensure standardized monitoring procedures.

\subsubsection{Capabilities}

The Phase I team is designed as a rapid response to provide operational capabilities to augment state, local, and RAP responders. Principally, this consists of interface to LFA and state/local representatives, limited monitoring and sampling, HPGe In Situ measurements, dose assessment, communications to home team support, and planning for follow-on assets. The primary products consist of:

- Plume projections (provided by home team support and/or field elements)

- Dose projections

- Contamination contours

- Assessed data to support protective action recommendations

- Integration of AMS data

- Contamination monitoring 
- Air sampling

- Isotopic mix determination

- Recommendations to support protective actions and dose reduction to the public

- Monitoring of radiation dose levels for the public and team members

- Secure communications

- Logistics planning

- In-field training capability

\subsubsection{Equipment}

Below is a brief summary of the equipment package deployed with the Phase I team. Modifications to the monitoring kits can be made for specific scenarios.

- Field monitoring instrument kits (6) [NRC ADM300A and TSA Violinists III]

- exposure rate

- alpha/beta/gamma contamination

- alpha deposition

- HPGe In Situ System (1)

- High volume air sampler (2)

- Laptops for data analysis (2)

- Health physics supplies

Dosimetry (Thermal Luminescent Dosimeters and Electronic Pocket Dosimeters)

Personal air samplers (6)

Personal protective equipment

Contamination control equipment

- GIS laptop and color printer (1)

- Laptop database (1)

- Communication kit

Cell phones/pagers (12)

Repeater (1)

Radios (12)

INMARSAT (1)

Approximate total weight: $1,500 \mathrm{lbs}$

\subsubsection{Response Posture}

Upon direction from DP-23, DOE/NV will contact DOE team members and initiate the Bechtel Nevada notification chain. DOE/NV and Bechtel Nevada home team support will be established as required. Personnel and equipment will be prepared to deploy within four (4) hours of notification, contingent upon availability of air transport (commercial or military). To provide maximum airlift flexibility, the Phase I team personnel and equipment makeup is designed to allow for deployment via commercial carrier. Contacts have been established with cognizant Federal agencies to ensure the viability of the commercial deployment option.

Upon arrival at the designated operations center, full Phase I operations can be established in less than three (3) hours. The only potential exception to this three-hour timeframe will be in the 
establishment of a duplex radio net, contingent on the timely access to a suitable repeater location. Phase I operations will commence sooner if the situation dictates that only a subset of the operational capability is required.

\subsubsection{Operations}

Upon establishing interfaces with representatives from the LFA, state, local, utility, RAP, Department of State, and/or other government entities, the Director and/or Operations Manager will establish the Phase I priorities.

Home teams at the national laboratories (Lawrence Livermore National Laboratory or Sandia National Laboratories) provide plume modeling. Data in standardized formats can be downloaded into the deployed GIS systems via standard clear and/or secure communications channels.

If required, the stand-by AMS team (fixed-wing aircraft deployed from Las Vegas, Nevada, or Washington, D.C.) can deploy as a self-contained element. Data in standardized formats generated by the AMS team can be integrated into the Phase I database. This information can be utilized to confirm modeling calculations, utilized to establish/modify the monitoring plan, and incorporated into the assessment process.

The Operations Manager, Assessment Supervisor, Monitoring Supervisor, and Health and Safety Specialist will jointly develop a monitoring plan based upon the input provided to the Director by the impacted government entities. Nominally, emphasis is placed on quickly characterizing the impact on population. Emphasis will be placed on key monitoring measurements that will benchmark existing modeling results and/or augment existing monitoring results (e.g., an HPGe In Situ measurement to determine/confirm the isotopic mix).

Phase I monitoring teams can operate independently or integrate with local and RAP personnel. Contingencies have been made to train local emergency responders and law-enforcement personnel on scene should the situation preclude DOE and DOE contractor personnel from performing monitoring and sampling operations.

The Health and Safety Specialist is responsible for ensuring the safety of the team members, ensuring the operations center is established in a safe, non-contaminated location, and for establishing contamination control procedures. The Health and Safety Specialist can be provided REAC/TS support via communications channels as necessary.

The Phase I team is designed to provide a rapid initial limited response for one-shift operations (12-18 hours maximum). Should additional resources be required, the Phase II or full FRMAC will be deployed. The Phase I team will make initial logistics arrangements for any follow-on DOE assets. 


\subsection{Phase II}

The Phase II team responds 1) to augment the Phase I team when it deploys in advance and 2) in a Phase I/Phase II combined response as a standard OCONUS capability. The team provides a 24-hour-a-day, extended timeframe operational capability.

\subsubsection{Team Makeup}

The Phase II team consists of an additional 45 DOE/NV and Bechtel Nevada contractor personnel (totaling 60 personnel when combined with the Phase I response):

- Deputy Director (DOE/NV)

- Deputy Operations Manager (DOE/NV)

- Public Affairs Officer (DOE/NV)

- Liaisons (2)

- Assessment Manager/Deputy Assessment Manager

- Assessment Scientist (2)

- Deputy Monitoring Manager

- Health and Safety Specialists (3)

- Support Manager

- Deputy Support Manager

- Communications Specialists (6)

- Logistics Specialist (6)

- GIS Scientists (3)

- Database Specialists (2)

- Monitoring Specialist (1) - HPGe In Situ

- Monitoring Specialists (13)

Figure 2 provides the field organization for the combined Phase I/Phase II response.

The job descriptions for most of the additional Phase II personnel closely match those described previously for the Phase I team. Many of the Phase II team members will be off-duty Phase I responders.

\subsubsection{Capabilities}

The Phase II team allows for extended 24-hour-a-day operations. In addition to extending the operating duration of the Phase I team, the Phase II response provides:

- Monitoring and support personnel to increase monitoring and sampling capabilities and to establish 24-hour operations. The integration of Phase II resources will allow rest periods to be established on a rotational basis.

- Complete logistical preparation for the arrival of the full FRMAC (obtaining resources such as meals, lodging, vehicles, etc.) for CONUS responses. The additional logistical personnel and equipment will be required for an OCONUS response to allow for ongoing operations. 
- A complete hotline for controlling the spread of radiological contamination. While domestic responses may have this capability via state and local responders, OCONUS operations will likely require this asset to be a part of RMAC.

- Industrial Hygiene monitoring capability. Some basic monitoring capabilities may be included in Phase $\mathrm{I}\left(\mathrm{O}_{2}\right.$, Lower Explosive Limit, $\left.\mathrm{CO}_{2}\right)$; however, the bulk of Industrial Hygiene monitoring assets will be a part of Phase II. Phase II will also include an Industrial Hygienist.

- Full comprehensive, traceable, and quality-assured database and documentation established.

- Fast secure data, voice, fax, and video links to home teams and other deployed elements. Ability to integrate data transmission into the DOE Emergency Communications Network.

- Full GIS capability to include workstations and large-bed plotters.

- Self-contained operation to include power generation and distribution

\subsubsection{Equipment}

Below is a brief summary of the additional assets to be deployed with the Phase II team.

- Field monitoring instrument kits (14) [NRC ADM300A and TSA Violinists III]

- exposure rate

- alpha/beta/gamma contamination

- alpha deposition

- HPGe In Situ System (1)

- High volume air sampler (8)

- GIS workstation (3)

- GIS plotters (2)

- Database workstations (4)

- Augmented communications

- Power generation and distribution

- Logistical support

\subsubsection{Response Posture}

Upon direction from DP-23, DOE/NV will contact DOE team members and initiate the Bechtel Nevada Phase II notification chain. DOE/NV and Bechtel Nevada home team support will be established as required. In the event that a Phase I team is deployed initially, contingency planning for a Phase II deployment will commence immediately.

The Phase II team will be staffed from off-duty Phase I team members and other pre-identified personnel. Past experience will be utilized to determine appropriate staffing levels at each billet to ensure that the Phase II team can be fully staffed in the required time frame. Random notification tests and personnel availability surveys will be utilized to validate the determined staffing levels.

The Phase II team is designed to be deployed via military aircraft (optionally DOE-certified contract aircraft). All Phase II assets will be stored in a constant deployment-ready state. 
Personnel and equipment will be prepared to deploy within seven (7) hours of notification, contingent upon availability of air transport (military).

Upon arrival at a designated operations center, the full Phase II operation will be established in less than four (4) hours. The only potential exception to this four-hour timeframe will be in the establishment of additional duplex radio nets, contingent on the timely access to a suitable repeater location. Phase II operations will commence sooner if the situation dictates that only a subset of the operational capability is required.

\subsubsection{Operations}

Should the Phase I/Phase II teams be deployed jointly, the initial operational priorities will be similar to those described for Phase I operations. If the Phase I team has already established operations, priority will be given to relieving personnel who have been working for extended periods of time.

The Director and/or Operations Manager will establish priorities for the Phase I/Phase II operation. Plume modeling will be provided by home teams at the national laboratories or by their deployed elements.

If required, the stand-by AMS team and additional AMS resources will deploy as a selfcontained element. Data in standardized formats generated by the AMS team(s) will be integrated into the Phase II data center. Monitoring and sampling plans will be developed as described for Phase I operations.

The Support group will arrange for all necessary logistical requirements and make arrangements for a full FRMAC operation, if deployed.

\subsection{Phase III - Full FRMAC}

Phase III represents a full buildup to the classic FRMAC response. The FRMAC is described in detail elsewhere. The full FRMAC field organization (e.g., Phase III) is provided in Figure 3.

\section{Summary}

The phased FRMAC/RMAC concept is designed to provide increased flexibility and responsiveness for the Department of Energy's consequence management capability. The Phase I response is primarily designed to provide a rapid limited operational capability for CONUS scenarios. The Phase II response augments the Phase I team and represents the default OCONUS option. The combined Phase I/Phase II operation provides a 24-hour-a-day extended monitoring, sampling, and assessment capability. The Phase I and Phase II teams can be integrated into a full FRMAC when the situation dictates this level of support. 
This report was prepared as an account of work sponsored by an agency of the United States Government. Neither the United States Government nor any agency thereof, nor any of their employees, nor any of their contractors, subcontractors or their employees, makes any warranty, express or implied, or assumes any legal liability or responsibility for the accuracy, completeness, or any third party's use or the results of such use of any information, apparatus, product, or process disclosed, or represents that its use would not infringe privately owned rights. Reference herein to any specific commercial product, process, or service by trade name, trademark, manufacturer, or otherwise, does not necessarily constitute or imply its endorsement, recommendation, or favoring by the United States Government or any agency thereof or its contractors or subcontractors. The views and opinions of authors expressed herein do not necessarily state or reflect those of the United States Government or any agency thereof.

This work was performed by Bechtel Nevada for the U.S. Department of Energy, Nevada Operations Office, under Contract No. DE-AC08-96NV11718.

By acceptance of this article, the publisher and/or recipient acknowledges the U.S. Government's right to retain a nonexclusive, royalty-free license in and to any copyright covering this article. 


\section{REFERENCES}

Federal Register, 48.90. Federal Radiological Emergency Response Plan (FRERP), May 8, 1996.

U.S DOE. Accident Response Group, DOE Order 5530.1 A, September 20, 1991. (a)

U.S. DOE, Aerial Measuring System, DOE Order 5530.4, September 20, 1991. (b)

U.S. DOE, Federal Radiological Monitoring and Assessment Center. DOE Order 5530.5, July 10, 1992, and Change 1, December 2, 1992. (a)

U.S. DOE, Radiological Assistance Program, DOE Order 5530.3, January 14, 1992, and Change 1, April 10, 1992. (b)

U.S. DOE Nevada Operations Office, Overview of FRMAC Operations. Doc. No. DOE/NV/11718-146, Rev. 4, March 1998.

U.S. DOE Nevada Operations Office, FRMAC Operations Manual-Emergency Phase, Doc. No. DOE/NV11718-080, May 1997.

Weinstein, E. and Hogan, R. Response Coordination Manual, U.S. NRC Division of Operational Assessment, Office for Analysis and Evaluation of Operational Data, Doc. No. NUREG/BR0230 September 1996. 


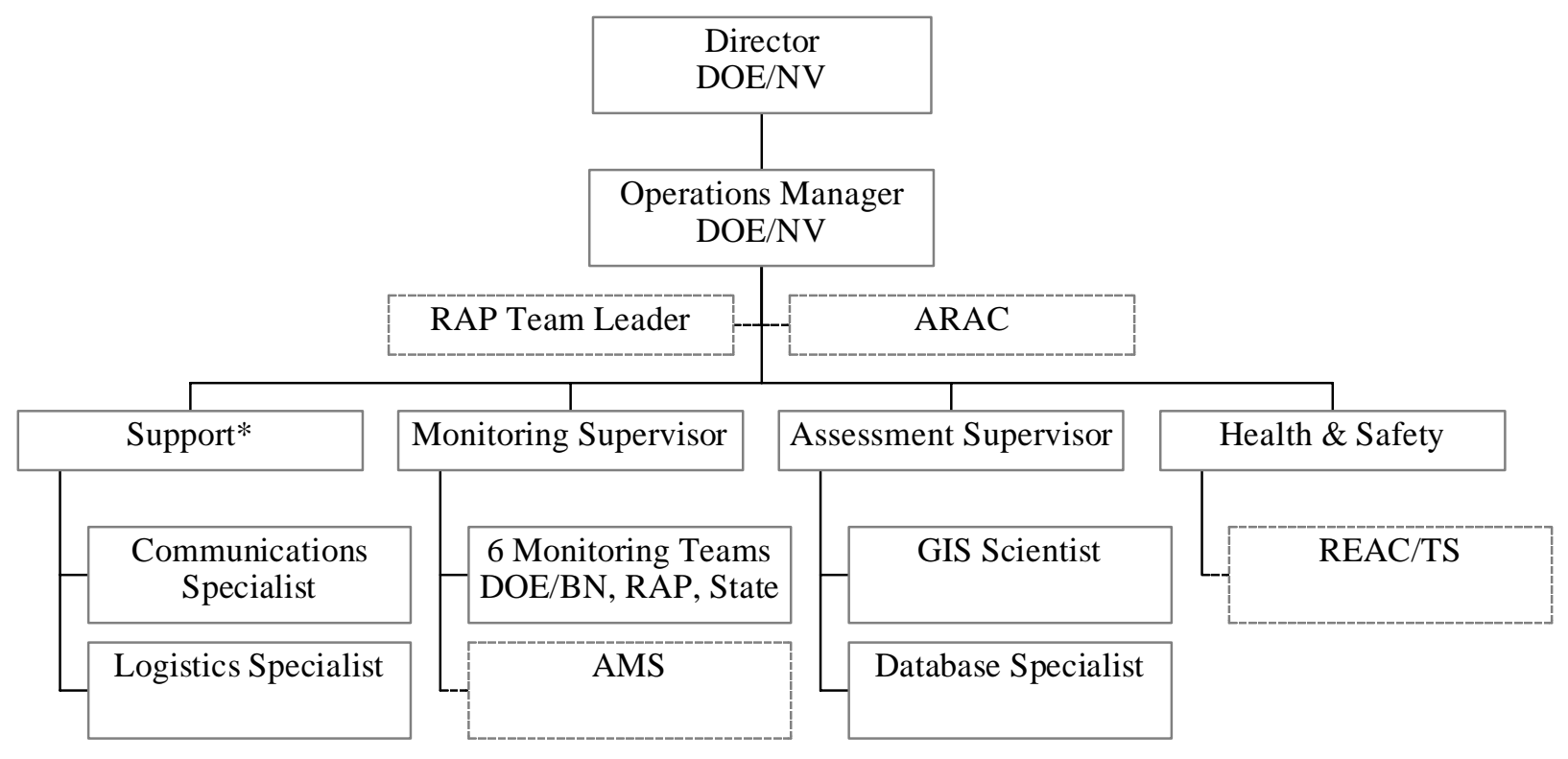

*Support Manager follows with Phase II.

Figure 1: The FRMAC/RMAC Phase I field organization. 


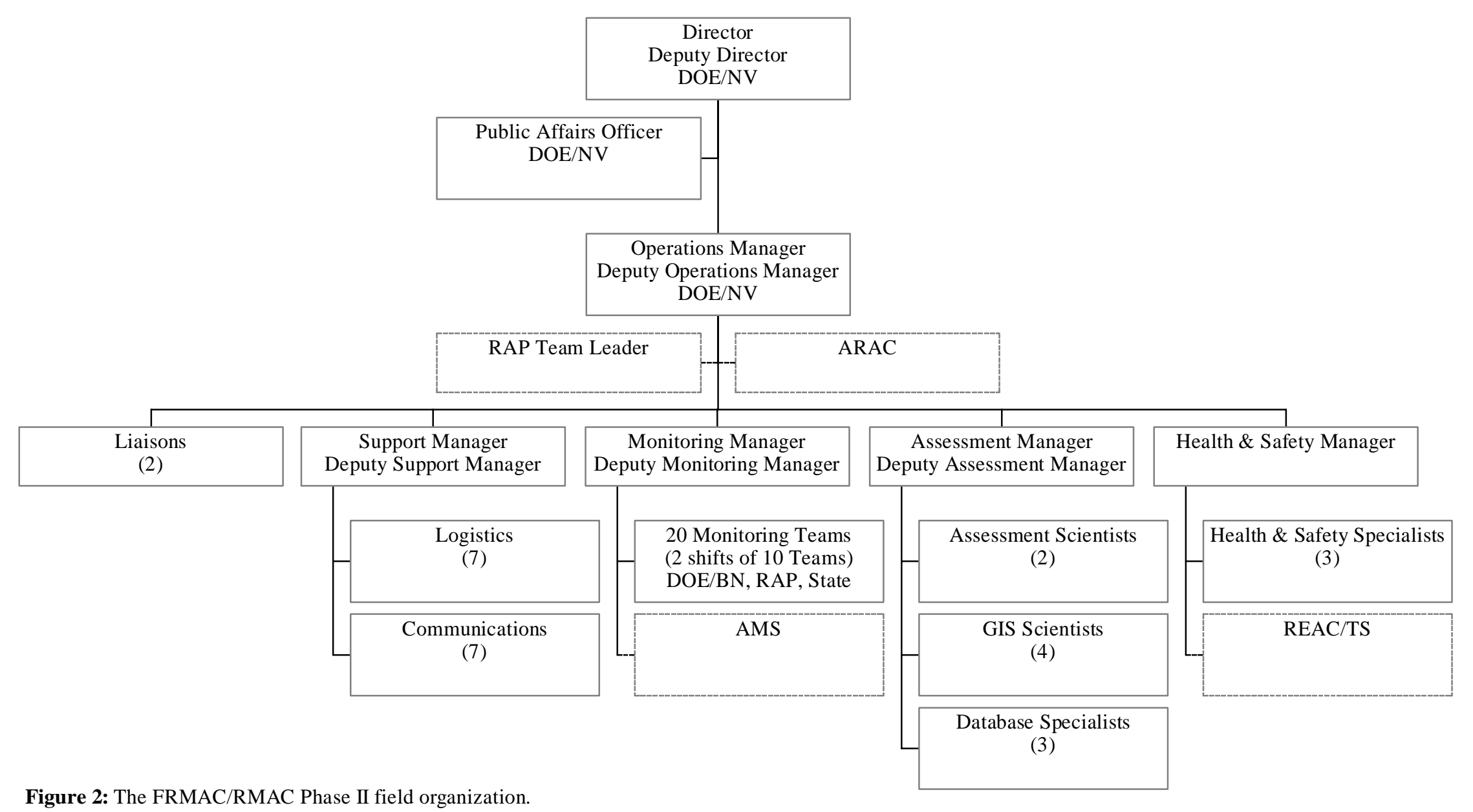




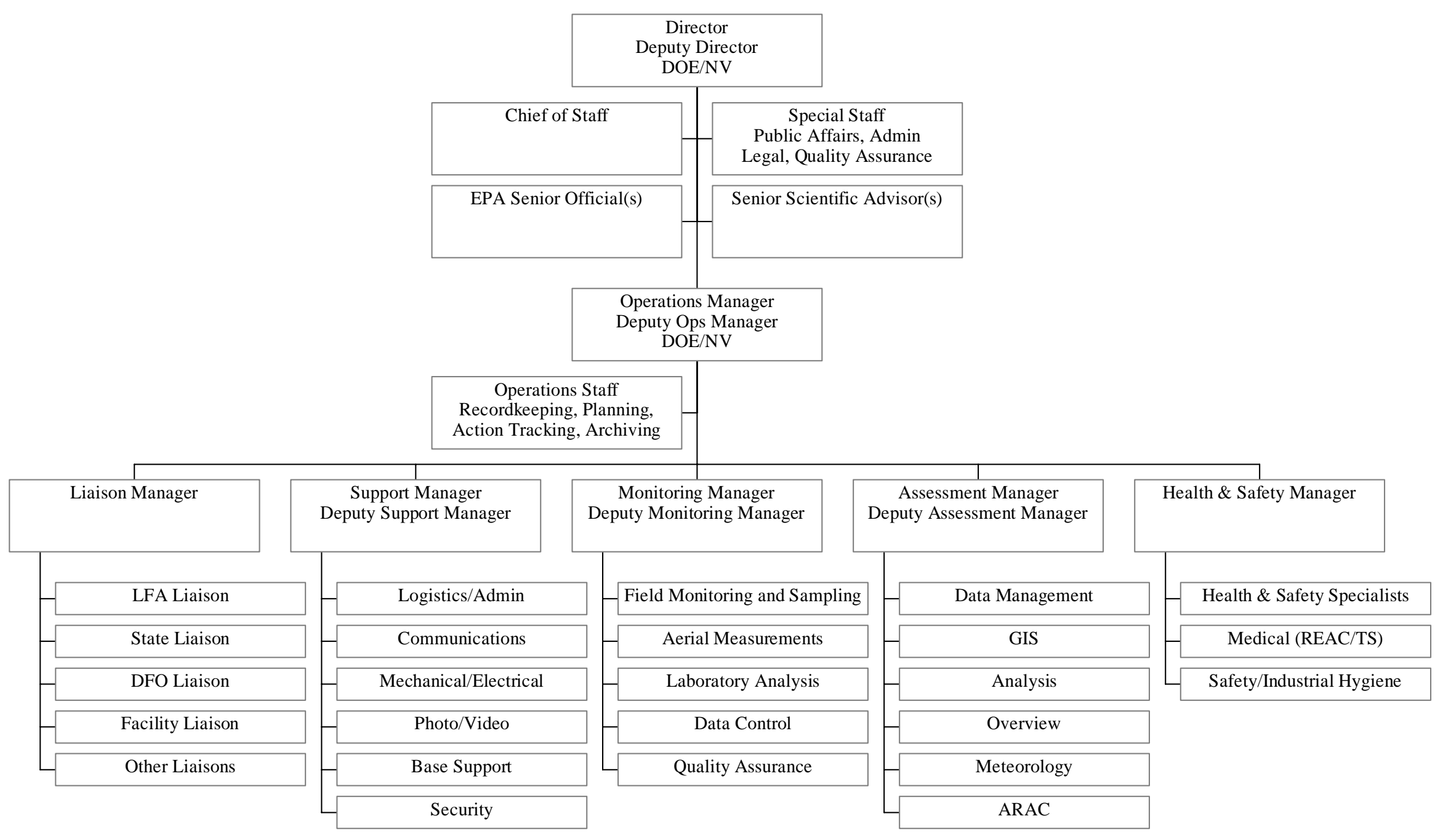

Figure 3: The full (Phase III) FRMAC field organization. 